\title{
Anaerobic Microbial Diversity and Abundance in Xinjiang Low-Temperature Water- Flooding Petroleum Reservoir
}

\author{
Lujun Chai ${ }^{1, *}$, Fan Zhang ${ }^{2}$, Yuehui She ${ }^{3}$, I. M. Banat ${ }^{4}$ and Xianqing $\mathrm{Li}^{1}$ \\ ${ }^{I}$ College of Geoscience and Surveying Engineering, China University of Mining and Technology (Beijing), Beijing 100083, China \\ ${ }^{2}$ School of Energy Resources, China University of Geosciences (Beijing), Beijing 100083, China \\ ${ }^{3}$ College of Chemistry and Environmental Engineering, Yangtze University, Jingzhou, Hubei 434023, China \\ ${ }^{4}$ School of Biomedical Sciences, University of Ulster, Coleraine BT52 ISA, N. Ireland, UK
}

Received 1 April 2017; Accepted 15 November 2017

\begin{abstract}
The important role of anaerobic microorganisms in oil recovery has attracted attention, but anaerobic microbial diversity and abundance in low-temperature water-flooding oil reservoir has not been studied. To investigate anaerobic microorganisms with diverse physiological and metabolic abilities in a low-temperature water-flooding petroleum reservoir in Xinjiang, China, four types of anaerobic microorganisms were enriched on the selective cultures, and microbial communities in four anaerobic enrichments and production water (PW) were analyzed based on construction of a 16S rRNA gene clone library. Analysis of 16S rRNA gene sequencing and phylogenetic diversity reveals that the reservoir harbours large amounts of anaerobic microorganisms. Arcobacter, Thalassolituus, Azoarcus, and Marinobacterium are predominant groups in the PW clone library. Acidaminobacter, Spirochaete, Spaerochaeta, and Geovibrio are dominant and have the potential to grow using hydrocarbons as carbon sources. Fermentative bacteria mainly belong to Spirochaete; the nitrate-reducing bacteria are Pseudomonas, Acidaminobater, Acetobacterium, Spirochaete, and Spaerochaeta; and the sulfate-reducing bacteria are closely related to Desulfovibrio, Desulfuromonas, Sulfurospirillum, and Spirochaete. Spirochaetes are present in the five samples indicating diverse metabolic abilities and indigenous presence in oil reservoirs. Knowledge of the predominant microbial communities in the reservoir conditions was proposed as a reference in formulating a strategy to enhance oil recovery through injection of selected nutrients or inhibitors to stimulate selective microbes.
\end{abstract}

Keywords: Microbial community, 16S rRNA, Clone library, Microbial enhanced oil recovery

\section{Introduction}

Petroleum reservoirs are populated mainly by anaerobic microorganisms because of low redox potential [1-3]. Since the first sulfate-reducing bacteria (SRB) were isolated from production water $(\mathrm{PW})$ in 1926, culture-dependent and independent methodologies, particularly $16 \mathrm{~S}$ rRNA-based molecular identification methods, have revealed diverse microorganisms inhabiting petroleum reservoirs [4, 5]. Anaerobic enrichments from oil reservoirs have shown that isolating hydrocarbon-degrading bacteria (HDB), fermentative bacteria (FB), nitrate-reducing bacteria (NRB), and SRB are the important populations in reservoir ecosystems, and have critical roles in the microbial enhancement of the oil recovery process [6].

Anaerobic microbial activity reported in oil reservoirs has diverse physiological and metabolic abilities that could be beneficial or detrimental to oil recovery. For example, HDB possess the ability to selectively hydrolyze oil components to methane and $\mathrm{CO}_{2}$ [7], resulting in increase of pressure in reservoirs, which enhances oil production. Anaerobic fermentative bacterial activity also produces

\footnotetext{
"E-mail address: sophyer@126.com

ISSN: $1791-2377$ (C) 2017 Eastern Macedonia and Thrace Institute of Technology. All rights reserved. doi:10.25103/jestr.106.17
}

gases, acids, and solvents that are believed to enhance oil recovery in many field trials of microbial enhancement of oil recovery (MEOR) [8]. In comparison, widespread presence of SRB in oil reservoirs is believed to be responsible for reducing oil quality and increasing refining costs of oil and gas due to the production of $\mathrm{H}_{2} \mathrm{~S}$ leading to the souring of oil [9]. A strategy of stimulating NRB by adding nitrate had been applied to reduce the activity of SRB based on the mechanism of competition for electrons or hydrogen [10].

The effective application of MEOR is generally believed to involve a combination of multiple microbial mechanisms utilizing groups of beneficial bacteria with different physiological and metabolic abilities or through the addition of selected chemicals, nutrients or manipulation of the environment [11]. Microorganisms are important participants for MEOR; therefore, a comprehensive insight into the microbial communities of oil reservoirs is essential in planning the field trial of MEOR [12]. Recently, the technology of $16 \mathrm{~S}$ rRNA gene clone library has provided significant insights into microbial diverse physiological and metabolic abilities in petroleum reservoirs. Voodrouw [13] suggested that fermentative bacteria, sulfide oxidizers and SRB could be potential bacterial syntrophs present in $25^{\circ} \mathrm{C}$ water-flooding oil reservoir. Grabowski et al. [14] investigated the microbial diversity in a non-water flooded $20{ }^{\circ} \mathrm{C}$ oil reservoir and observed that many anaerobic microorganisms were involved in the food chain in this oil 
Lujun Chai, Fan Zhang, Yuehui She, I. M. Banat and Xianqing Li/

Journal of Engineering Science and Technology Review 10 (6) (2017) 129-135

reservoir. However, anaerobic microbial diversity at lowtemperature water-flooding oil reservoirs remains scarce.

In this study, 16S rDNA clone libraries were performed to investigate the distribution and abundance of anaerobic microbial community of HDB, FB, NRB, and SRB and the PW from the low-temperature water-flooding petroleum reservoir in Xinjiang, China. This reservoir would improve oil recovery by stimulating reservoir microorganisms because of lower water-flooding efficiency. Therefore, the primary objective of the study is to provide ecological information on microbial populations and the biological control potential for SRB. This study also aims to understand the significance of these anaerobic bacteria in oil recovery processes and to utilize beneficial microbes in future applications of MEOR in such oil reservoirs.

The rest of this paper is organized as follows. Section 2 presents the materials and methods in detail. Section 3 describes the results and discussions of the study, and finally, the conclusions are summarized in Section 4.

\section{Materials and methods}

\subsection{Sample collection}

The PW was collected directly from the wellhead of production well T6073 in Xinjiang No. 6 oilfield on July 20, 2016. Oil-water samples were placed in sterile $500 \mathrm{ml}$ serum bottles, and then sealed with rubber stoppers to maintain anoxic condition; and then, the samples were transported to the laboratory immediately for further analysis. The in situ temperature was $20.6{ }^{\circ} \mathrm{C}$ with approximately $800 \mathrm{~m}$ depth, and crude oil viscosity was $80 \mathrm{mPa} \cdot \mathrm{s}$. The formation water salinity is approximately $5000 \mathrm{mg} / \mathrm{L}$.

\subsection{Enrichment of anaerobic microorganisms}

Four types of anaerobic enrichment cultures were conducted using selective media inoculated with PW from the Xinjiang No. 6 oilfield. Each $100 \mathrm{ml}$ medium was placed in a $250 \mathrm{ml}$ serum bottle and flushed with a mixture of $\mathrm{N}_{2}$ and $\mathrm{CO}_{2}$ (4:1, under atmospheric pressure) for $30 \mathrm{~min}$ to eliminate oxygen from the medium. Resazurin $(0.5 \mathrm{mg} / \mathrm{L})$ served as a redox indicator. The media were inoculated with $10 \%(\mathrm{v} / \mathrm{v})$ PW. Petroleum from the same oil field was sterilized in hermetically sealed ampules for $30 \mathrm{~min}$ at $0.5 \mathrm{~atm}$ to use as carbon sources in some of these enrichments.

Anaerobic hydrocarbon-degrading bacteria (HDB) were enriched using R medium containing sterilized oil (2\%) [15]. The fermentative bacteria (FB) group was enriched for use of the medium supplemented with peptone $(5.0 \mathrm{~g} / \mathrm{L})$ and glucose $(10.0 \mathrm{~g} / \mathrm{L})$ [16]. Nitrate-reducing bacteria (NRB) were enriched in Adkins medium with sodium citrate (8.5 $\mathrm{g} / \mathrm{L})$ as the energy and sodium nitrate as the electron acceptor [17]. Sulfate-reducing bacteria (SRB) were obtained using Postgate's B medium containing sodium thiosulfate $(10.0 \mathrm{~g} / \mathrm{L})$, sodium lactate $(4.0 \mathrm{~g} / \mathrm{L})$, and sodium ascorbate $(4.0 \mathrm{~g} / \mathrm{L})$ and then supplemented with microelements and reductant of $\mathrm{Na}_{2} \mathrm{~S} \cdot 9 \mathrm{H}_{2} \mathrm{O}(200 \mathrm{mg} / \mathrm{L})$ [18]. All media were incubated at $20{ }^{\circ} \mathrm{C}$ for 14 days.

\subsection{Genomic DNA extraction}

After the preceding steps, $100 \mathrm{ml} \mathrm{PW} \mathrm{sample} \mathrm{and} 5 \mathrm{ml}$ anaerobic enrichments were centrifuged to pellet cells. Following the manufacturer's instruction for TIANamp Micro DNA Kit (DP316) (Tian Gen Biotech (Beijing) Co.
Ltd., China), genomic DNA was extracted in triplicate to avoid bias and the DNAs were mixed.

\subsection{Construction of 16S rRNA gene libraries}

The 16S rRNA gene was amplified by PCR using universal bacteria primers $27 \mathrm{~F} / 1492 \mathrm{R}$. Bacteria $16 \mathrm{~S}$ rRNA gene amplifications were conducted with template DNA following the previous PCR reacting system and thermal cycle programme [19].

Amplicons were cloned with a TA cloning vector kit (Promega, Madison, WI, USA) according to the manufacturer's instruction. Five clone libraries were constructed for the DNAs extracted from PW and the four anaerobic enrichment cultures. Then, 200 clones in each clone library were obtained to select positive clones through PCR with the sets of vector-specific primers T7/SP6. PCR products of positive clones were subjected to amplified ribosomal DNA restriction analysis (ARDRA) with Hinfl and HaeIII (Fermentas, Lithuania) [20].

\subsection{Data analysis}

Clones were classified into different operational taxonomic units (OTU) based on ARDRA profiles. Representative clones, belonging to different OTUs, were selected for $16 \mathrm{~S}$ rDNA sequencing. Clone libraries were statistically evaluated by rarefaction analysis using Analytic Rarefaction 1.3 in which the expected numbers of different ARDRA groups versus the numbers of positive clones in each library were calculated. Shannon indices characterize the $16 \mathrm{~S}$ rDNA clone libraries [21].

Sequencing was conducted using an ABI PRISM 3730 DNA sequencer (SinoGenoMax Co. Ltd., Beijing, China). The obtained sequences were manually checked and edited using DNAMAN version 5.2.2.0. Using a BLAST search tool, a representative sequence from each OTU was compared with sequences in the GenBank database to find the most closely related sequences and organisms. Sequences with more than $97 \%$ similarity were considered to be the same phylotype. Neighbour-joining tree was constructed by using ClustalX version 1.83 and MEGA version 4.1 [22, 23]. Bootstrap analysis with 1000 resamplings was conducted to assign confidence levels to the nodes in the distance and parsimony trees.

\section{Results and discussions}

3.1 Statistical analysis of $16 \mathrm{~S}$ rRNA gene clone libraries for four anaerobic enrichments and production water

To investigate the main anaerobic microbial communities within a low-temperature oil reservoir subjected to long-term water flooding, the PW retrieved directly from one production well was used in anaerobic enrichments designed to obtain four clone libraries, namely, HDB for hydrocarbon-degrading bacteria, FB for fermentative bacteria, NRB for nitrate-reducing bacteria, and SRB for sulfate-reducing bacteria. Meanwhile, microorganisms in PW are also analyzed using a $16 \mathrm{~S}$ rDNA clone library. Based on sets of vector-specific primers T7/SP6, 948 positive clones out of a total of 1000 clones in the five clone libraries are identified.

According to ARDRA profiles, the number of positive clones in the clone libraries of PW, FB, HDB, NRB, and SRB are identified as $14,7,12,11$, and 12 OTUs, respectively. The richness of OTUs observed in the rarefaction curves is higher in the $\mathrm{PW}$ than in the four 
Lujun Chai, Fan Zhang, Yuehui She, I. M. Banat and Xianqing Li/

Journal of Engineering Science and Technology Review 10 (6) (2017) 129-135

anaerobic cultures. Moreover, rarefaction curves of the five clone libraries tend to approach the saturation plateau, indicating that the positive clones in the clone library could effectively cover the diversity of microorganisms (Fig. 1).

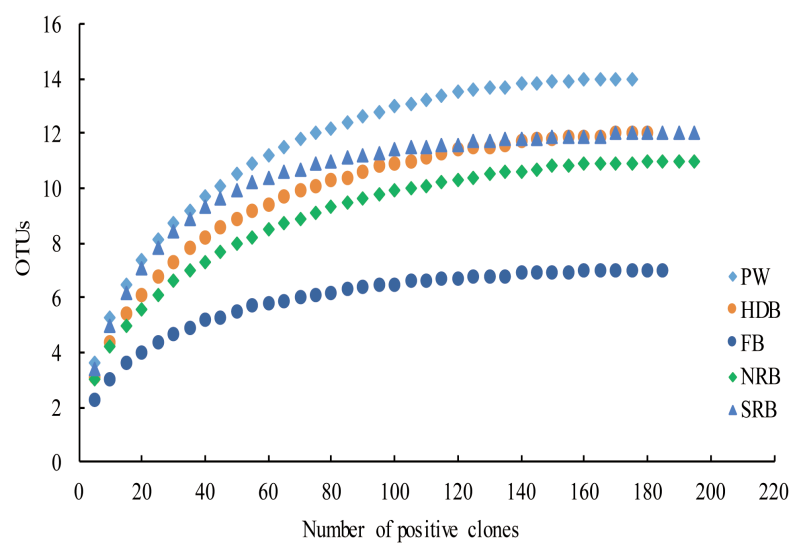

Fig. 1. Rarefaction analysis of 16S rRNA gene positive clones for clone libraries of PW, FB, HDB, SRB, and NRB using software of Analytic Rarefaction

The Shannon index of bacterial diversity was calculated to assess the evenness of the OTU distribution. NRB has the highest Shannon index (Tab. 1), indicating that the highest bacterial diversity was present in NRB; in contrast, FB has the lowest Shannon's index (1.32).

Table 1. Statistical analysis of five clone libraries

\begin{tabular}{lccccc} 
Table 1. Statistical analysis of five clone libraries & \\
\hline Library & PW & FB & HDB & NRB & SRB \\
\hline $\begin{array}{l}\text { Number of } \\
\text { Positive clones }\end{array}$ & 176 & 190 & 186 & 198 & 198 \\
\hline OTUs & 14 & 7 & 12 & 11 & 12 \\
\hline Shannon & 2.05 & 1.32 & 2.06 & 2.32 & 1.98 \\
\hline Simpson & 0.63 & 0.48 & 0.66 & 0.76 & 0.69 \\
\hline
\end{tabular}

3.2 Anaerobic microbial communities in the lowtemperature water-flooding oil reservoir

The diversity and relative abundance of microbial communities in the four anaerobic enrichments and the production water are shown in Fig. 2. The predominant group in the clone library of PW is Arcobacter, which accounts for $58 \%$, while the clone libraries of HDB, FB, $\mathrm{NRB}$, and SRB are predominated with microbial groups affiliated with Acidaminobacter, Sphaerochaeta, Pseudomonas, and Desulfovibrio, which accounts for 54\%, $24 \%, 39 \%$, and $48 \%$, respectively. The remaining bacterial sequences of the PW clone library are mainly of the genera Thalassolituus, Azoarcus, Marinobacterium, Sulfurimonas, Azovibrio, and Desulfomicrobium. In HDB, many microorganisms, such as Acidaminobacter, Spirochaete, Spaerochaeta, Geovibrio, Arcobater, and Acetobacterium, have the potential to use hydrocarbons. Unclassified bacteria accounted for $68 \%$, are the most frequently detected in the FB. The remaining genera of NRB are mainly Acidaminobater, Acetobacterium, Spirochaete, and Spaerochaeta, while the remaining genera of SRB are closely related to Desulfuromonas, Sulfurospirillum, Brachymonas, and Spirochaete.
Numerous microorganisms are detected in the PW sample and not observed in the anaerobic enrichment cultures (Fig. 2). Aerobic and anaerobic microorganisms Azovibrio, Azoarcus, and Arcobacter are identified in the PW. Moreover, Spirochaeta appeared in all of the five samples, which indicates that the genus has diverse metabolic abilities in an oil-bearing environment. Additionally, Sphaerochaeta is also detected in HDB and NRB. Desulfovibrio is present in HDB and FB, while Denitrovibrio is identified in FB and NRB. Unclassified bacteria are detected in all samples, especially the dominant group in the FB library.

\subsection{Phylogenetic diversity analysis of Anaerobic microbial populations in the oil reservoir}

To further analyze the microbial diversity of the lowtemperature water-flooding oil reservoir, the sequences of five clone libraries were used to construct a phylogenetic tree with closely related bacterial sequences. The phylogenetic diversity is displayed in a phylogenetic tree (Fig. 3).

Microbial communities are significantly different between the production water and the four anaerobic enrichments. For example, microaerophilic bacteria Azovibrio restrictus, Azoarcus communis, and Arcobacter defluvi are detected in PW [24]. Water flooding is always regarded as a significant factor that influences oxygen content [25], which affects native microbial communities in oil reservoirs. The sample was collected from the oil reservoir subjected to long-time water flooding since 1974. Moreover, microbial communities show that the dominant microbes among the five clone libraries are different at phylum level. e-proteobacteria is the dominant group in the PW library, while the predominant groups of known cultivated bacteria are closely related to Firmicutes, $\alpha$ proteobacteria, $\gamma$-proteobacteria, and $\delta$-proteobacteria in the HDB, FB, NRB, and SRB enrichment cultures, respectively.

Notably, however, Firmicutes is not detected in PW and Defferribacteres is identified in HDB. The reasons for these differences are as follows. First, the four anaerobic enrichment cultures adopt selective media to enrich culturespecific species, while the PW retrieved from the reservoir directly is used to extract genomic DNA predominating under the reservoir conditions. Second, we investigate only the microbial communities in the water sample in this study without considering other parameters such as strata pressure, crude oil, and formation water, which are significant environmental factors for anaerobic enrichment. Third, various biases occur in the extraction of genomic DNA and TA clones as well as in PCR amplification [19].

Limited knowledge is available on microbial diversity in complex oil field environments and thus, only a few species have been reported [12]. New species may exist in the lowtemperature water-flooding oil reservoir. Sequences related to Brachymonas petroleovorans (94\% identity) and Desulfuromonas michiganensis (93\%-96\% identity) in the SRB sample, and to Pseudobutyrivibrio ruminis (94\%) in the FB sample have been detected and had less than $97 \%$ similarity to the species reported in the previous papers. Unclassified bacteria are obtained in all samples, indicating which the oil reservoir harbours a unique community of novel bacterial species or genera. 
Lujun Chai, Fan Zhang, Yuehui She, I. M. Banat and Xianqing Li/

Journal of Engineering Science and Technology Review 10 (6) (2017) 129-135

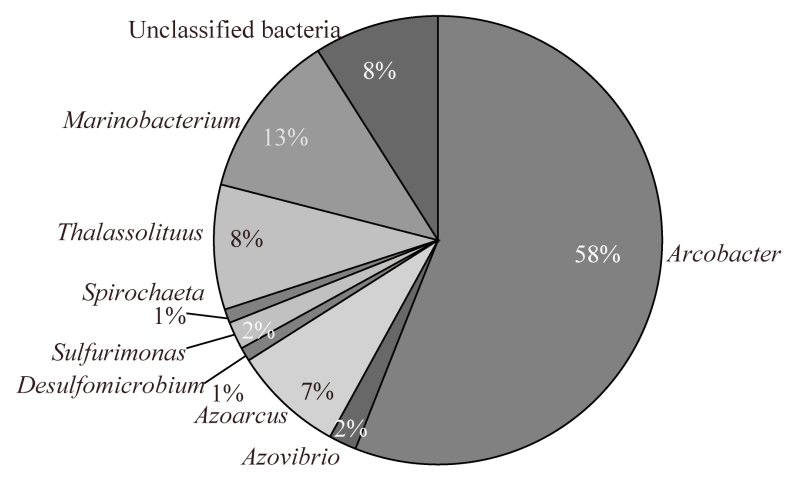

PW
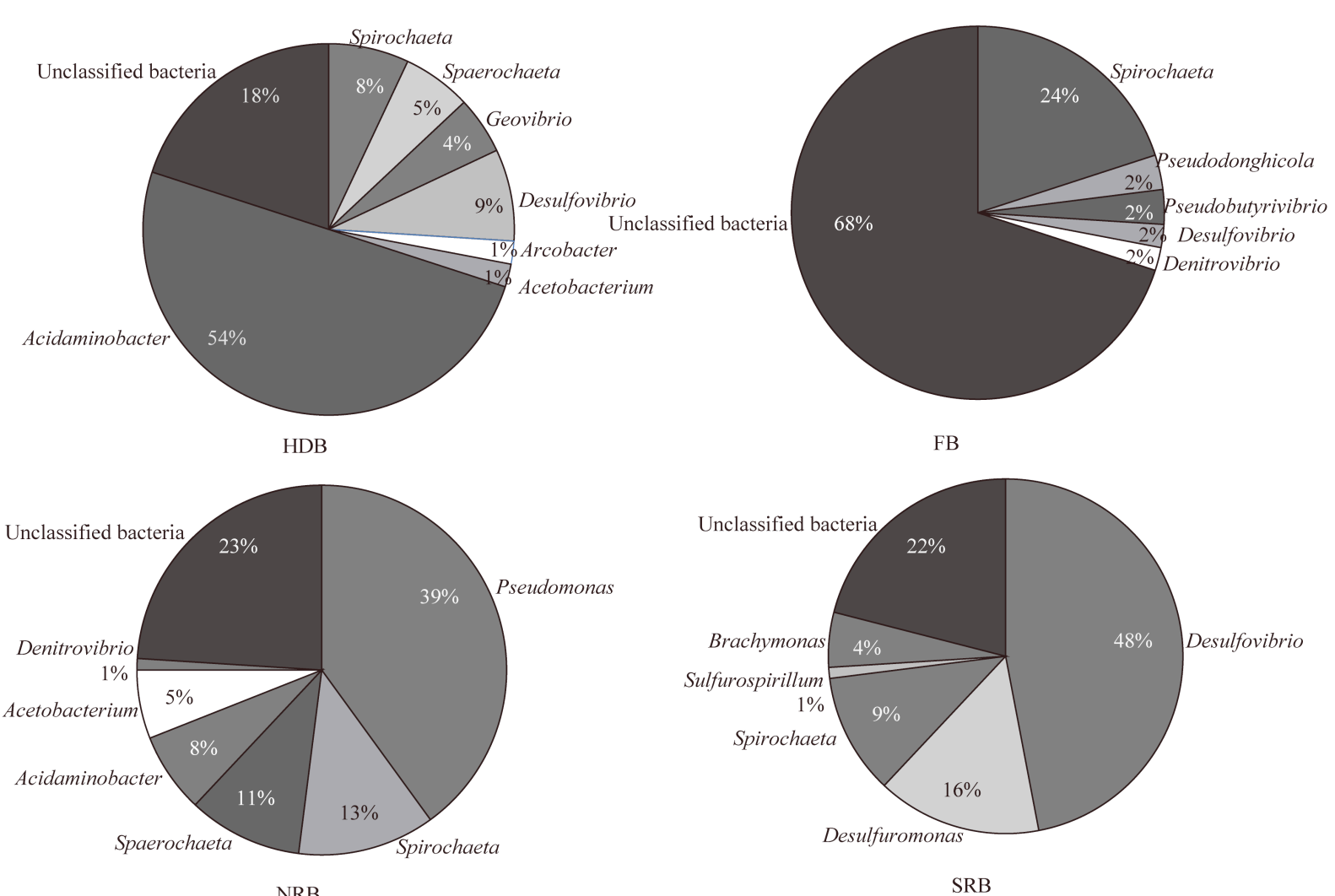

SRB

Fig. 2. Relative abundances and diversity of microbial community in production water (PW) and anaerobic enrichments clone libraries (FB, HDB, $\mathrm{SRB}$, and NRB)

\subsection{Potential microorganisms to microbial enhanced oil recovery}

In the study, the four selective anaerobic media were used to enrich FB, HDB, NRB, and SRB, and then microorganisms that are both beneficial and detrimental to MEOR appear in the four anaerobic enrichment cultures and the PW. Thalassolituus oleivorans and Brachymonas petroleovorans could grow using hydrocarbons as carbon sources [26, 27]. Acidaminobacter hydrogenoformans and pseudobutyrivibrio ruminis are also identified and could be selectively activated for their metabolites $[28,29]$, thereby reducing oil viscosity or interfacial tension and leading to increased production of biomass production to improve oil recovery.

Denitrifying bacteria, such as Pseudomonas stutzeri and Denitrovibrio acetiphilus [30-32], are present in the NRB. However, bacterial sequences of SRB are assigned to
Desulfovibrio caledoniensis, Desufovibrio dechloracetivorans, and Geovibrio thiophilu. Therefore, enhancing or stimulating the activity of such strains could be useful when SRBs are detrimental or become a problem for MEOR due to the production of $\mathrm{H}_{2} \mathrm{~S}$ [6].

\subsection{Indigenous Spirochaetes in oil reservoirs}

Spirochaetes are detected in the four anaerobic enrichments and the PW. The study reveals that Spirochaetes could exhibit diverse metabolic abilities in the low-temperature water-flooding oil reservoir. Additionally, mesophilic fermentative halophilic Spirochaeta smaragdinae was isolated from an African oil field [33]. Moreover, Spirochaetes were obtained in a low-salinity non-flooded 20 ${ }^{\circ} \mathrm{C}$ oil reservoir in water-flooding Enermark oil fields and in a non-flooded high-temperature oil reservoir [14, 34, 35]. 
Lujun Chai, Fan Zhang, Yuehui She, I. M. Banat and Xianqing Li/

Journal of Engineering Science and Technology Review 10 (6) (2017) 129-135

Thus, Spirochaetes could be considered as indigenous bacteria in oil reservoirs.

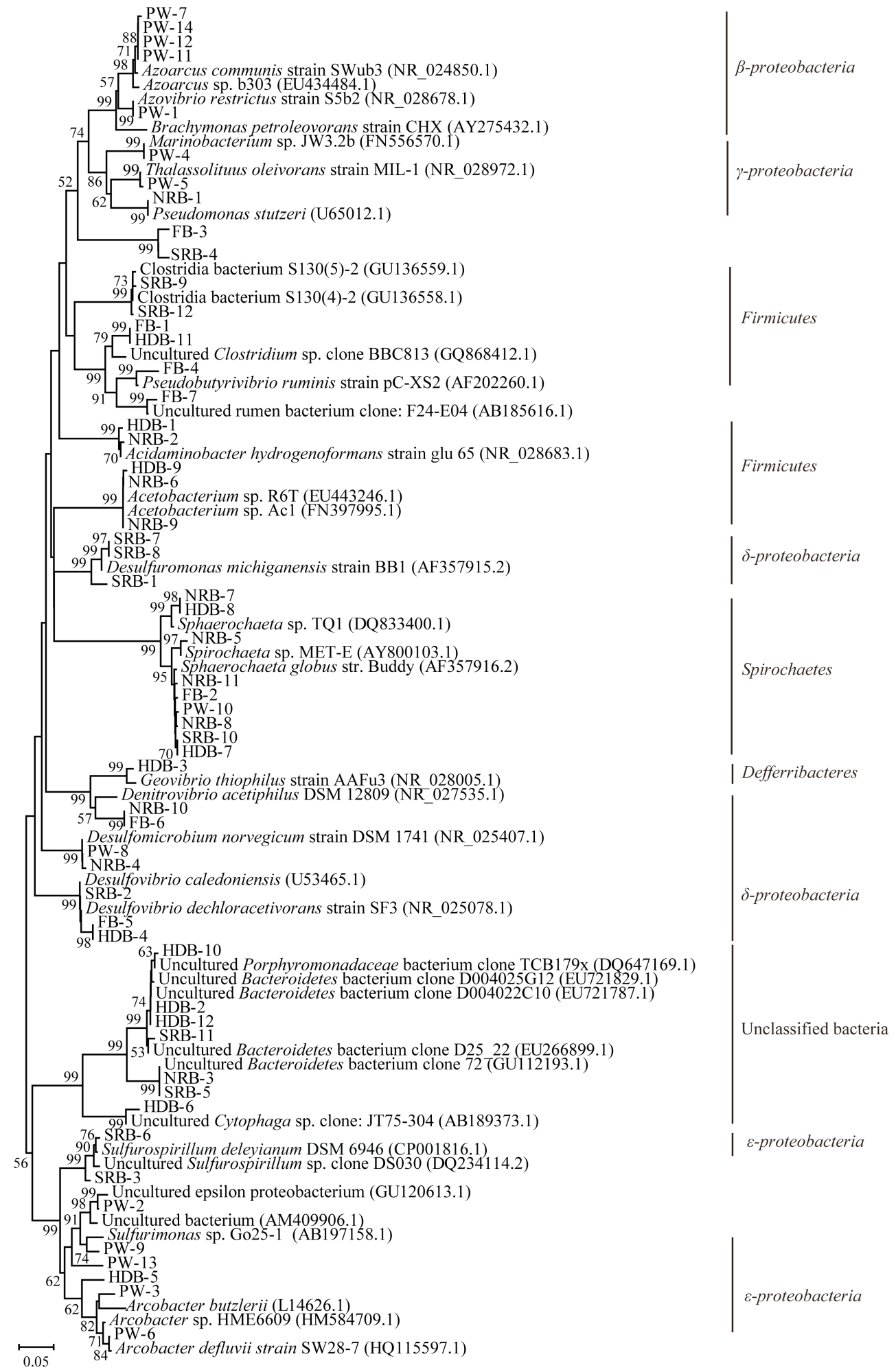

Fig. 3. Phylogenetic tree of $16 \mathrm{~S}$ rDNA phylotypes of four anaerobic enrichments and production water clone libraries

\section{Conclusions}

To provide ecological information on oil recovery and biological control potential for SRB in the Xinjiang lowtemperature water-flooding petroleum reservoir, this study set up four types of anaerobic enrichment cultures using four selective media for $\mathrm{HDB}, \mathrm{FB}, \mathrm{NRB}$, and SRB. Then, $16 \mathrm{~S}$ rDNA clone library, gene sequencing, and phylum diversity analysis were conducted to reveal the distribution and abundance of anaerobic microbial populations in the oil reservoir. The following conclusions could be drawn:

(1) Beneficial bacteria to microbial enhanced oil recovery are identified. Hydrocarbon-degrading bacteria, fermentative bacteria, and nitrate-reducing bacteria are detected in the petroleum reservoir. Beneficial bacterial communities could be enhanced through injection of chemicals such as surface-active molecules or selected nutrients or through manipulation of culture conditions. 
Lujun Chai, Fan Zhang, Yuehui She, I. M. Banat and Xianqing Li/

\section{Journal of Engineering Science and Technology Review 10 (6) (2017) 129-135}

Furthermore, beneficial microorganisms could be used to enhance oil recovery in the low-temperature water-flooding oil reservoir.

(2) SRB bacteria are most numerous in the oil reservoir and cause substantial damage to oil recovery. Knowledge of the presence of detrimental SRB bacteria can be mitigated by using selected inhibitors or simulating NRB activity.

(3) The bacterial sequences of the four anaerobic enrichments and the PW closely related to the genus Spirochaetes, which has diverse metabolic abilities in the low-temperature water-flooding oil reservoir, could be considered as indigenous in petroleum reservoirs.

Thus, the study was applied to MEOR in the oil reservoir by injecting proper nutrients, activating selectively beneficial microorganisms, and inhibiting the detrimental ones in the reservoir. The role of anaerobic microorganisms in the reservoir conditions remains ambiguous because of their diverse metabolic abilities and therefore could be further investigated.

\section{Acknowledgements}

The authors are grateful for the support provided by National Science and Technology Major Project(No. 2016ZX05007003) and the National Natural Science Foundation of China (No. 41673047, 41572125).

This is an Open Access article distributed under the terms of the Creative Commons Attribution Licence

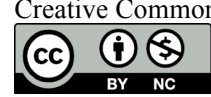

\section{References}

1. Aitken, C. M., Jones, D. M., Larter S.R., "Anaerobic hydrocarbon biodegradation in deep subsurface oil reservoirs". Nature, 431, 2004, pp. 291-294.

2. Li, H., Wang, X. L., Mu, B. Z, Gu, J. D., Liu, Y. D., Lin, K. F., Lu, S G., Lu, Q., Li, B. Z., Li, Y. Y., Du, X. M., "Molecular detection, quantification and distribution of alkane-degrading bacteria in production water from low temperature oilfields". International Biodeterioration and Biodegradation, 76(1), 2013, pp. 49-57.

3. Gao, P., Tian, H., Li, G., Sun, H., Ma, T., "Microbial diversity and abundance in the Xinjiang Luliang long-term water-flooding petroleum reservoir". MicrobiologyOpen, 4(2), 2015, pp. 332-342.

4. Lenchi, N., Kebbouche-Gana M. L., Gana, M., Llirós, M., Servais, P., García-Armisen, T., "Diversity of microbial communities in production and injection waters of Algerian oilfields revealed by 16S rRNA Gene Amplicon 454 Pyrosequencing". PLoS One, 8(6), 2013, e66588.

5. Okoro, C., Smith, S., Chiejina, L., Lumactud, R., An, D., Park, H. S., Voordouw, J., Lomans, B. P., Voordouw, G., "Comparison of microbial communities involved in souring and corrosion in offshore and onshore oil production facilities in Nigeria". Journal of Industrial Microbiology and Biotechnology, 41(4), 2014, pp. 665-678.

6. Youssef, N., Elshahed, M. S., McInerney, M. J. "Microbial processes in oil fields: culprits, problems, and opportunities". Advances in applied microbiology, 66, 2009, pp. 141-251.

7. Zengler, K., Richnow, H. H., Rosselló-Mora, R., Michaelis, W., Widdel, F., "Methane formation from long-chain alkanes by anaerobic microorganisms". Nature, 401, 1999, pp. 266-269.

8. Nakano, M. M., Dailly, Y. P., Zuber, P., Clark, D. P., "Characterization of anaerobic fermentative growth of Bacillus subtilis: identification of fermentation end products and genes required for growth". Journal of Bacteriology, 179(21), 1997, pp. 6749-6755.

9. Gao, P. K., Li, G. Q., Zhao, L. X., Dai, X. C., Tian, H. M., Dai, L. B., Wang, H. B., Huang, H. D., Chen, Y. H., Ma, T., "Dynamic processes of indigenous microorganisms from a low-temperature petroleum reservoir during nutrient stimulation". Journal of Bioscience and Bioengineering, 117(2), 2014, pp. 215-221.

10. Bødtker, G., Thorstenson, T., Lillebø, B. L., Thorbjørnsen, B. E., Ulvøen, R. H., Sunde, E., Torsvik, T., "The effect of long-term nitrate treatment on SRB activity, corrosion rate and bacterial community composition in offshore water injection systems". Journal of Industrial Microbiology and Biotechnology, 35(12), 2008, pp. 1625-1636.

11. Ian, M., and Neil, D. G., "Microbial Biotechnology 2020; microbiology of fossil fuel resources". Microbial Biotechnology, 9(5), 2016, pp. 626-634.

12. Magot, M., Ollivier, B., Patel, B. K., "Microbiology of petroleum reservoirs". Antonie Van Leeuwenhoek, 77(2), 2000, pp. 103-116.

13. Voordouw, G., "Production-related petroleum microbiology: progress and prospects". Current Opinion in Biotechnology, 22(3), 2011, pp. 401-405.

14. Grabowski, A., Nercessian, O., Fayolle, F., Blanchet, D., Jeanthon, C., "Microbial diversity in production waters of a low-temperature biodegraded oil reservoir". FEMS Microbiology Ecology, 54(3), 2005, pp. 427-443.
15. Nazina, T. N., Rozanova, E. P., Kuznetsov, S. I., "Microbial oil transformation processes accompanied by methane and hydrogen sulfide formation". Geomicrobiology Journal, 4(2), 1985, pp. 103130.

16. Nazina, T.N., and Rozanova, E. P., "Ecologic conditions for the spread of methane-forming bacteria in the petroleum strata of Apsheron". Mikrobiologiia, 49(1), 1980, pp. 123-129.

17. Adkins, J. P., Cornell, L. A., Tanner, R. S., "Microbial composition of carbonate petroleum reservoir fluids". Geomicrobiology Journal, 10(2), 1992, pp. 87-97.

18. Postgate, J. R., "Media for sulphur bacteria". Practice Labs, 15(11), 1966, pp. 1239-1244.

19. Zhang, F., She, Y. H., Ma, S. S., Hu, J. M., Banat, I. M., Hou, D. J., "Response of microbial community structure to microbial plugging in a mesothermic petroleum reservoir in China". Applied Microbiology and Biotechnology, 88(6), 2010, pp. 1413-1422.

20. Lagacé, L., Pitre, M., Jacques, M., Roy, D., "Identification of the bacterial community of maple sap by using amplified ribosomal DNA (rDNA) restriction analysis and rDNA sequencing”. Applied and Environmental Microbiology, 70(4), 2004, pp. 2052-2060.

21. Caporaso, J. G., Kuczynski, J., Stombaugh, J., Bittinger, K., Bushman, F. D., Costello, E. K., Fierer, N., Peña, A. G., Goodrich, J. K., Gordon, J. I., Huttley, G. A., Kelley, S. T., Knights, D., Koenig, J. E., Ley, R. E., Lozupone, C. A., McDonald, D., Muegge, B. D., Pirrung, M., Reeder, J., Sevinsky, J. R., Turnbaugh, P. J., Walters, W. A., Widmann, J., Yatsunenko, T., Zaneveld, J., Knight, R., "QIIME allows analysis of high-throughput community sequencing data". Nature Methods, 7(5), 2010, pp. 335-336.

22. Tamura, K., Nei, M., Kumar, S., "Prospects for inferring very large phylogenies by using the neighbor-joining method". Proceedings of the national academy of sciences of the united states of America, 101(30), 2004, pp. 11030-11035.

23. Tamura, K., Dudley, J., Nei, M., Kumar, S., "MEGA4: molecular evolutionary genetics analysis (MEGA) software version 4.0". Molecular Biology and Evolution, 24(8), 2007, pp. 1596-1599.

24. Collado, L., Levican, A., Perez, J., Figueras, M. J., "Arcobacter defluvii sp. nov., isolated from sewage samples". International journal of systematic and evolutionary microbiology, 61(9), 2011, pp. 2155-2161.

25. Dahle, H., Garshol, F., Madsen, M., Birkeland, N. K., "Microbial community structure analysis of produced water from a hightemperature North Sea oil-field". Antonie Van Leeuwenhoek, 93(12), 2008, pp. 37-49.

26. Rouviere, P. E., and Chen, M. W., "Isolation of Brachymonas petroleovorans $\mathrm{CHX}$, a novel cyclohexane-degrading betaproteobacterium". FEMS Microbiology Letters, 227(1), 2003, pp. 101-106.

27. Yakimov, M. M., Giuliano, L., Denaro, R., Crisafi, E., Chernikova, T. N., Abraham, W. R, Luensdorf, H., Timmis, K. N., Golyshin, P.N., "Thalassolituus oleivorans gen. nov., sp. nov., a novel marine bacterium that obligately utilizes hydrocarbons". International journal of systematic and evolutionary microbiology, 54(1), 2004, pp. 141-148. 
Lujun Chai, Fan Zhang, Yuehui She, I. M. Banat and Xianqing Li/

Journal of Engineering Science and Technology Review 10 (6) (2017) 129-135

28. Meijer, W.G., Nienhuis-Kuipe,r M. E., Hansen, T. A., "Fermentative bacteria from estuarine mud: phylogenetic position of Acidaminobacter hydrogenoformans and description of a new type of gram-negative, propionigenic bacterium as Propionibacter pelophilus gen. nov., sp. nov". International Journal of Systematic Bacteriology, 49(3), 1999, pp. 1039-1044.

29. Grilli, D. J., Cerón, M. E., Paez, S., Egea, V., Schnittger, L., Cravero, S., Escudero, M. S., Allegretti, L., Arenas, G. N., "Isolation of Pseudobutyrivibrio ruminis and Pseudobutyrivibrio xylanivorans from rumen of Creole goats fed native forage diet". Folia Microbiologica, 58(5), 2013, pp. 367-373.

30. Peña, A., Busquets, A., Gomila, M., Bosch, R., Nogales, B., GarcíaValdés, E., Lalucat, J., Bennasar, A., "Draft genome of Pseudomonas stutzeri strain ZoBell (CCUG 16156), a marine isolate and model organism for denitrification studies". Journal of Bacteriology, 194(5), 2012, pp. 1277-1278.

31. Fan, Y., Tao, W., Huang, H., Li, S., "Characterization of a novel bioemulsifier from Pseudomonas Stutzeri". World Journal of Microbiology and Biotechnology, 33(8), 2017, p. 161.
32. Myhr, S., and Torsvik, T., "Denitrovibrio acetiphilus, a novel genus and species of dissimilatory nitrate-reducing bacterium isolated from an oil reservoir model column". International journal of systematic and evolutionary microbiology, 50(4), 2000, pp. 16111619.

33. Magot, M., Fardeau, M.L., Arnauld, O., Lanau, C., Ollivier, B., Thomas, P., Patel, B. K., "Spirochaeta smaragdinae sp. nov., a new mesophilic strictly anaerobic spirochete from an oil field". FEMS Microbiology Letters, 155(2), 1997, pp. 185-191.

34. Kryachko, Y., Dong, X., Sensen, C. W., Voordouw, G., "Compositions of microbial communities associated with oil and water in a mesothermic oil field". Antonie Van Leeuwenhoek, 101(3), 2012, pp. 493-506.

35. Kobayashi, H., Endo, K., Sakata, S., Mayumi, D., Kawaguchi, H., Ikarashi, M., Miyagawa, Y., Maeda, H., Sato, K., "Phylogenetic diversity of microbial communities associated with the crude-oil, large-insoluble-particle and formation-water components of the reservoir fluid from a non-flooded high-temperature petroleum reservoir". Journal of Bioscience and Bioengineering, 113(2), 2012, pp. 